\title{
Critical appraisal of omega- 3 fatty acids in attention-deficit/hyperactivity disorder treatment
}

This article was published in the following Dove Press journal:

Neuropsychiatric Disease and Treatment

26 July 2016

Number of times this article has been viewed

\section{Anja Königs \\ Amanda J Kiliaan}

Department of Anatomy, Donders Institute for Brain, Cognition \& Behaviour, Radboud University Medical Center, Nijmegen, the Netherlands
Correspondence: Amanda J Kiliaan Department of Anatomy, Radboud University Medical Center, Geert

Grooteplein Noord 2I, 6525 EZ

Nijmegen, the Netherlands

Tel +3I 2436 I 4378

Fax +3I 243613789

Email amanda.kiliaan@radboudumc.nl
Abstract: Attention-deficit/hyperactivity disorder (ADHD) is a common neurodevelopmental disorder. The classical treatment of ADHD where stimulant medication is used has revealed severe side effects and intolerance. Consequently, the demand to search for alternative treatment has increased rapidly. When comparing levels of omega-3 polyunsaturated fatty acids $(\omega-3$ PUFAs) in ADHD patients with those in age-matching controls, lower levels are found in ADHD patients' blood. $\omega$-3 PUFAs are essential nutrients and necessary for a proper brain function and development. Additionally, there are strong indications that $\omega-3$ PUFA supplements could have beneficial effects on ADHD. However, the results of $\omega$-3 PUFA supplementation studies show a high variability. Therefore, we reviewed recent studies published between 2000 and 2015 to identify effective treatment combinations, the quality of design, and safety and tolerability of $\omega$-3-containing food supplements. We searched the databases MEDLINE, PubMed, and Web of Science with keywords such as "ADHD" and " $\omega-3 / 6$ PUFA" and identified 25 studies that met the inclusion and exclusion criteria. The results of these $\omega$-3 PUFA studies are contradictory but, overall, show evidence for a successful treatment of ADHD symptoms. Tolerability of the given supplements was high, and only mild side effects were reported. In conclusion, there is evidence that a $\omega$-3 PUFA treatment has a positive effect on ADHD. It should be added that treatment could be more effective in patients with mild forms of ADHD. Moreover, the dosage of stimulant medication could be reduced when used in combination with $\omega-3$ PUFA supplements. Further studies are necessary to investigate underlying mechanisms that can lead to a reduction of ADHD symptoms due to $\omega-3$ PUFA treatments and also to determine the optimal concentrations of $\omega-3$ PUFAs, whether used as single treatment or in combination with other medication.

Keywords: ADHD, $\omega-3$ fatty acids, treatment, DHA, EPA

\section{Introduction to the emerging use of omega-3 in attention-deficit/hyperactivity disorder}

Attention-deficit/hyperactivity disorder (ADHD) is a neurodevelopmental disorder, which has its onset in childhood but can also persist until adulthood. ${ }^{1}$ The overall pooled prevalence of ADHD in the world is $7.2 \%$ but differs between sex and age. ${ }^{2-4}$ In general, prevalence of ADHD is higher in males than in females and is most common in schoolaged children. On the basis of criteria stated in the Diagnostic and Statistical Manual of Mental Disorders (DSM), ADHD patients can be divided into three groups: mainly inattentive, mainly hyperactive/impulsive, or a combination of both. ${ }^{1}$ The diagnosis is based on a number of age-dependent symptoms of inattention and/or hyperactivity/ impulsivity that should occur for a period of at least 6 months. These symptoms often lead to severe problems in social behavior as well as in peer relationships. For ADHD patients, social life in a family environment and at school/work is therefore difficult. submit your manuscript Dovepress fy http://dx,doi.org/10.21471NDTS68652 C. hereby accept the Terms. Non-commercial uses of the work are permitted without any further permission from Dove Medical Press Limited, provided the work is properly attributed. For permission for commercial use of this work, please see paragraphs 4.2 and 5 of our Terms (https://www.dovepress.com/terms.php). 
Furthermore, ADHD is often accompanied with learning difficulties and mood and behavior disorders. ${ }^{5}$ Problems in social life are the main reason for ADHD treatment.

One of the most commonly used treatments for ADHD is the stimulant drug called methylphenidate. Due to side effects and unknown long-term effects, however, there are concerns about the use of methylphenidate. ${ }^{6}$ These concerns are the main reason for families to postpone methylphenidate treatment for months to years after a confirmed diagnosis of ADHD by a physician. The most important reason for families to start using methylphenidate as treatment for ADHD is the ultimate urge to solve problems at school, work, and home. This kind of stimulant medication is only treating symptoms however, and not the cause. This means that the drug is only effective for a couple of hours after intake (half-life time of intermediate-release methylphenidate is $2-4$ hours) but will not change the situation over the long term. ${ }^{7}$ Studies have shown that stimulant drugs provoke mild side effects in most patients but also cause severe side effects, such as decreased appetite, insomnia, and headaches. ${ }^{8,9}$ These general concerns and side effects of the stimulant treatment clearly accentuate the need to search for alternative and less harmful treatments for ADHD. The best known alternative treatment is supplementation with omega-3 polyunsaturated fatty acids ( $\omega-3$ PUFAs).

It is interesting to use $\omega-3$ PUFAs as treatment for ADHD since ADHD patients in general show a lack of $\omega-3$ PUFAs. ${ }^{10-13}$ To understand the function of $\omega-3$ PUFAs, the family of $\omega-6$ PUFAs also need to be considered. The precursors of both $\omega-3$ and $\omega-6$ families are essential nutrients, which means that they cannot be produced by the body itself and should be obtained via dietary intake. In addition to the reliance on intake of essential PUFAs, processing of the precursors is inefficient in humans. ${ }^{14}$ During the Paleolithic period, the diet provided sufficient $\omega$-3 PUFAs due to the high intake of fish. The ratio of $\omega-3$ to $\omega-6$ PUFAs was therefore high. In the western diet, the ratio is low due to an increase in $\omega-6$ PUFAs and decrease in $\omega-3$ PUFAs. ${ }^{15-17}$ Furthermore, ADHD is multifactorial and depends on genetic background on the one hand, and, for a large part on environmental factors on the other hand. Reduced $\omega-3$ PUFAs levels in ADHD could be an interesting additional environmental factor because these deficiencies clearly have the greatest impact during the development of the central nervous system. This is also the time of onset of ADHD. This leads to the question whether a food supplement containing $\omega-3$ PUFAs can serve as an alternative treatment for ADHD, taking into consideration that there are less side effects, a higher efficiency and less concerns about the impact on health. The purpose of this article is to critically review recent literature on $\omega-3$ PUFAs treatment for ADHD, to determine 1) effective treatment combinations, 2) the quality of design of the clinical trials, and 3 ) the safety and tolerability of the food supplements.

\section{Rationale for $\omega$-3 in ADHD}

To clarify the hypothesis that supplements containing $\omega-3$ PUFAs could be used as effective ADHD treatment, the role of $\omega$-3 PUFAs in the healthy brain in comparison with the brain of an ADHD patient needs to be discussed. When precursors of $\omega-3$ and $\omega-6$ long chain PUFAs (LCPUFAs) enter the body, they enter the same enzyme pathway. The precursor $\alpha$-linolenic acid (ALA) belongs to the group of $\omega$-3 PUFAs and can be found in flax and in small amounts in soybeans, canola oil, and green leafy vegetables. The precursor can be converted into docosahexaenoic acid (DHA), which forms an important part in the production of phospholipids in neuronal membranes in the brain. DHA is responsible for fluidity and permeability of the neuronal membrane. High concentrations are found particularly in synapses, which makes DHA necessary for the function of neurons. An important intermediate is eicosapentaenoic acid (EPA), which is responsible for the production of eicosanoids. These eicosanoids can function as anti-inflammation signaling molecules. ${ }^{18}$ High concentrations of DHA and EPA are found in fish and fish oil.

Eicosanoids are also responsible for the regulation of the interaction of the $\omega-3$ and $\omega-6$ PUFA pathways. In addition to eicosanoids, the ratio between $\omega-3$ and $\omega-6$ PUFAs is also responsible for the regulation of both the pathways. A high intake of $\omega-6$ PUFAs may inhibit the production of $\omega-3$ PUFAs from its precursor and benefit processing of $\omega-6$ PUFAs. The $\omega-6$ PUFAs precursor is linoleic acid (LA) and is transformed into arachidonic acid (AA) as an important intermediate. In addition to EPA, AA produces anti-inflammatory eicosanoids, which can also be found in reasonable amounts in neuronal membranes. ${ }^{18}$ The final product is docosapentaenoic acid (DPA), which has inflammatory effects. ${ }^{18}$

Several arguments why $\omega$-3 PUFAs may serve as good candidates for the treatment of ADHD can be found in literature. These arguments are based on the biochemical and physiological functions of $\omega-3$ PUFAs. First, membranes of neurons contain high amounts of $\omega-3$ and $\omega-6$ PUFAs, especially DHA and AA, for proper neuronal function. The amount of $\omega-3$ and $\omega-6$ PUFAs affects the fluidity of the membrane, which could affect neurotransmission, 
permeability, as well as structure and function of membranebound proteins. In blood and plasma of ADHD patients, the level of $\omega-3$ PUFAs is lower than in age-matching controls. These lower levels can be found in children, adolescent, and adults. ${ }^{10-13}$ Postmortem measurements of the cortex showed that DHA concentration in a healthy brain increases until the age of 18 years. ${ }^{19}$ Furthermore, $\omega-3$ PUFAs have an important function in brain development. ${ }^{20-23}$ This could explain why $\omega$-3 PUFA deficiency during development has a wide impact on the function and development of the brain.

The second argument concerns the ratio of $\omega-3 / \omega-6$ PUFAs in blood and plasma cells, which is lower in patients with ADHD. The relatively higher amount of $\omega-6$ PUFAs may increase neuroinflammation. Since ADHD patients and controls consume similar amounts of $\omega-3$ and $\omega-6$ PUFAs, it is likely to presume that there are other causes for this change in ratio. ${ }^{10,13}$ One possible cause could be that processing of PUFAs is less effective in patients with ADHD. ${ }^{13}$ Common signs of essential fatty acid deficiency in ADHD patients are skin rashes and increased thirst. ${ }^{10}$ It is presumed that these symptoms are due to a deficiency in $\omega-6$ PUFAs. ${ }^{24}$ In any case, it should be added that there is no competition between $\omega-3$ and $\omega-6$ PUFAs during uptake but only at processing level. ${ }^{25}$ This offers the opportunity to increase the amount of $\omega-3$ PUFAs through higher dietary intake.

\section{Search methodology}

The following databases were searched between January 2000 and March 2016: MEDLINE, PubMed, and Web of Science. For this search, keywords such as Attention Deficit Hyperactivity Disorder (ADHD), $\omega-3$ and $\omega-6$ (long chain) poly unsaturated fatty acids (LCPUFAs), DHA, EPA, $\gamma$-linolenic acid (GLA), ALA, and fish oil were used. Other relevant information was also searched in references of reviews, studies, and meta-analyses. Inclusion criteria for trials were 1) a treatment with $\omega-3$ PUFAs or in combination with $\omega-6$ PUFAs, 2) a study design of open-labeled studies excluding a placebo group or double-blind studies including a placebo group, and 3) a diagnosis or suspicion of ADHD. Studies where ADHD was accompanied by the presence of a comorbidity were also included. As additional treatment, antioxidants such as vitamin $E$ and carriers such as phospholipids, which improve the availability of PUFAs for the body, were included as well. Trials related to other deficiencies in combination with $\omega-3$ PUFA deficiency such as zinc are excluded. Titles and abstracts of identified articles were controlled for inclusion and exclusion criteria. A flow diagram of the study selection is provided in Figure 1.

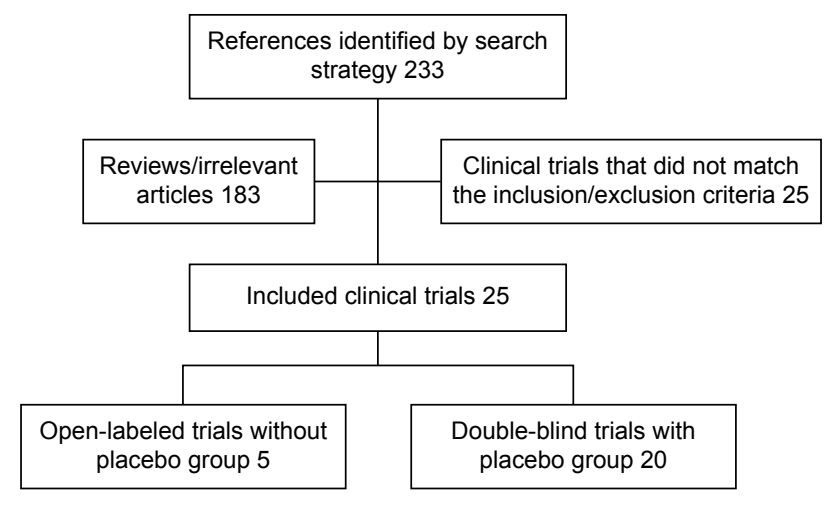

Figure I Flow diagram of study selection.

\section{Results}

In several studies, it has been indicated that a supplementation of $\omega-3$ PUFAs has a beneficial effect on ADHD symptoms. ${ }^{26-30}$ However, results of these studies show a high variability and inconsistency about its effect on ADHD. In this review, only studies that were published between 2000 and 2015 are included. First, general information about all selected trials is provided followed by separate discussion on the results of each trial. These studies are divided into open-labeled trials without the presence of a placebo group (Table 1) and double-blind trials with the presence of a placebo group (Table 2).

The subjects who participated in these trials were mostly school-aged children from 6 to 13 years old. In fact, the total age range was $3.5-18$ years. The predominant sex is male which is in accordance with the prevalence of ADHD in the population. In most cases, physicians officially diagnosed these children with ADHD in accordance with DSM-IV criteria. ${ }^{31-33}$ An alternative method used for the diagnosis of ADHD was via the criteria set in the Conners ADHD Index or Conners Rating Scale; scores higher than the 90th percentile in the parent-rated were used. ${ }^{28,29,34,35}$ Some studies also included children who had not been officially diagnosed with ADHD but who showed signs similar to children with ADHD. ${ }^{11,27-29,36-38}$

When taking comorbidity into account, it is evident that there are many common comorbid conditions associated with ADHD, which makes a homogeneous subject group difficult. In most studies, children with comorbidities of severe disorders were excluded. Examples of these disorders are neurological disorders and diseases such as epilepsy, mental retardation, autism spectrum disorder, mental insufficiency, encephalic malformations, including mechanical damage like a head injury leading to temporary loss of consciousness. Milder comorbidities such as 


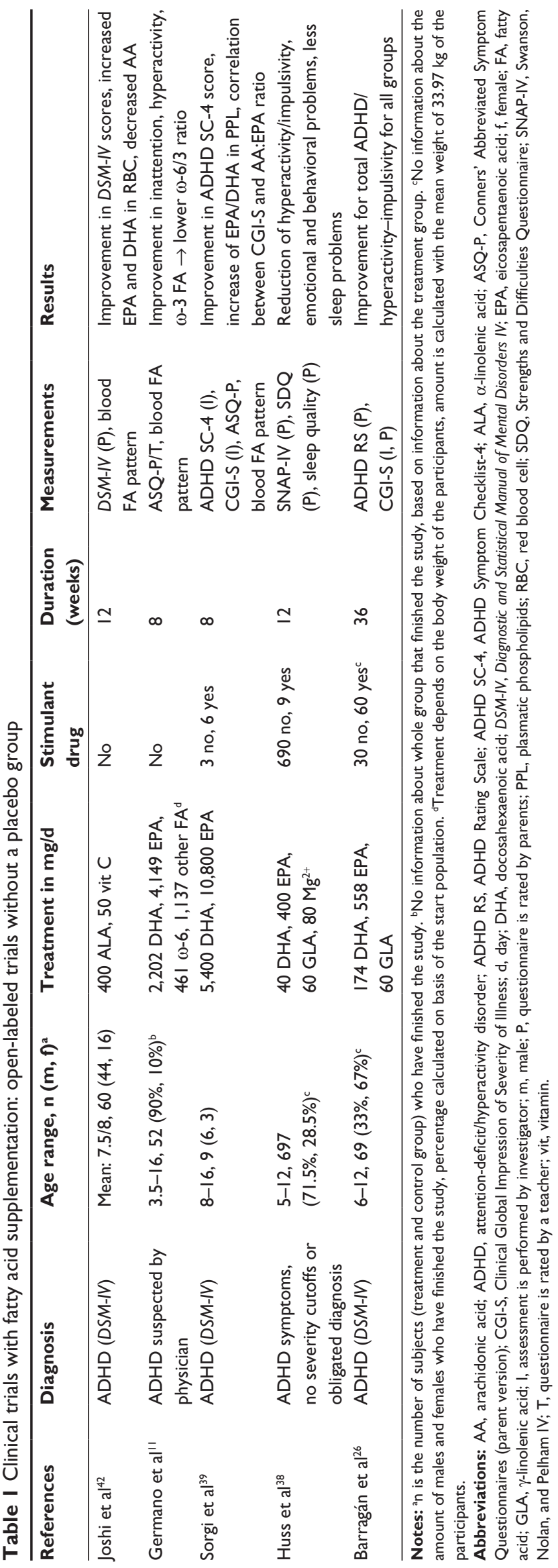

learning difficulties, developmental coordination disorder, oppositional defiant disorder, and conduct disorder were not excluded. ${ }^{31,34,36}$ Often, children were already treated both for ADHD and for the comorbid disorder before participating in studies with $\omega$-3 PUFAs. In most studies, children were asked to cease taking stimulant medication for the period of study. In case of treatment with stimulant medication, a washout period was often added.

The number of included subjects taking part in these studies varied considerably, that is, from 9 to 697 subjects. Some of the studies involving smaller number of subjects were pilot studies, thus explaining the small subject group in some cases. ${ }^{11,26,36,39-41}$ Studies reported various duration; from 8 up to 36 weeks. Trial length of most studies varied from 8 to 16 weeks. During this period of time, children's behavior was investigated; questionnaires were completed by parents and/or teachers and/or investigator. In addition, a few studies included cognitive tests to investigate the attention of the children. In some of these studies, the fatty acid profile of blood and/or plasma cells as well as physiological parameters were included, in order to control side effects of food supplements. Side effects are discussed in more detail in the section "Safety and tolerability".

\section{Results of nonplacebo-controlled trials}

The effects of PUFAs in ADHD symptoms were investigated in five open-labeled studies excluding placebo groups. ${ }^{11,26,38,39,42}$ All the five studies showed improvement in ADHD symptoms in behavioral questionnaires, which were rated by parents and/or investigators. In three of these studies, improvement in behavior was found, in addition to a positive effect in the blood fatty acid profile..$^{11,39,42}$ In the study of Barragán et al, ${ }^{26}$ an interesting design was used: a comparison was made between 1) a food supplement consisting of PUFAs, 2) stimulant medication, and 3) a combination of both. ${ }^{26}$ The food supplement consisted of $174 \mathrm{mg}$ DHA, $558 \mathrm{mg}$ EPA, and $60 \mathrm{mg}$ GLA. Results showed that a combined treatment of a food supplement with stimulant medication is not more effective than when merely taking methylphenidate, but resulted in less side effects. Food supplementation-only treatment is less effective than when taking only stimulant medication or taking a combination of both. This is a valuable information for scientists involved in designing less harmful treatments for ADHD. It should be added that there were variations in diet used in these reviewed studies. In four studies, a combination of DHA and EPA was used. In all the studies, DHA content was lower than that of EPA. 


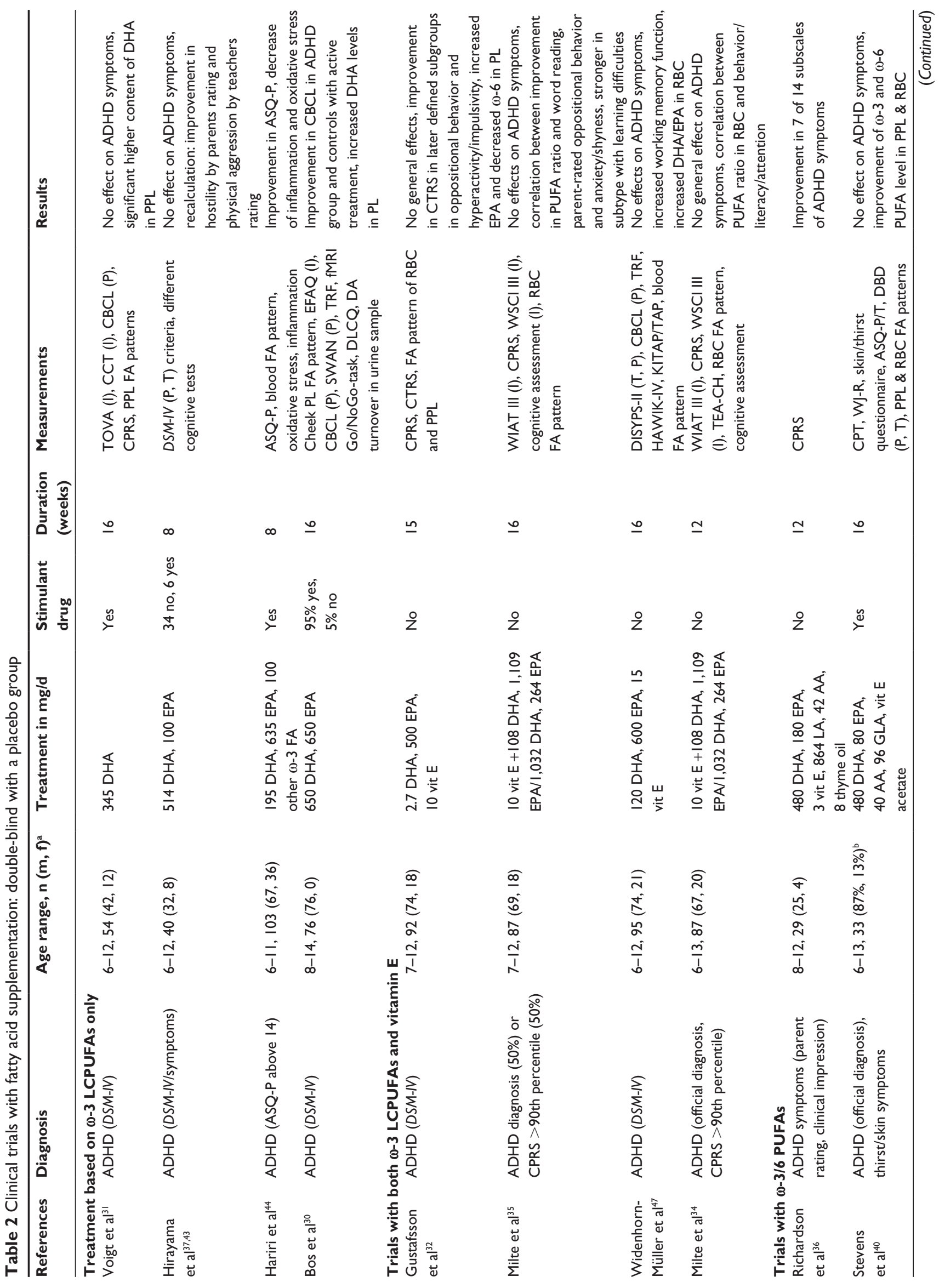




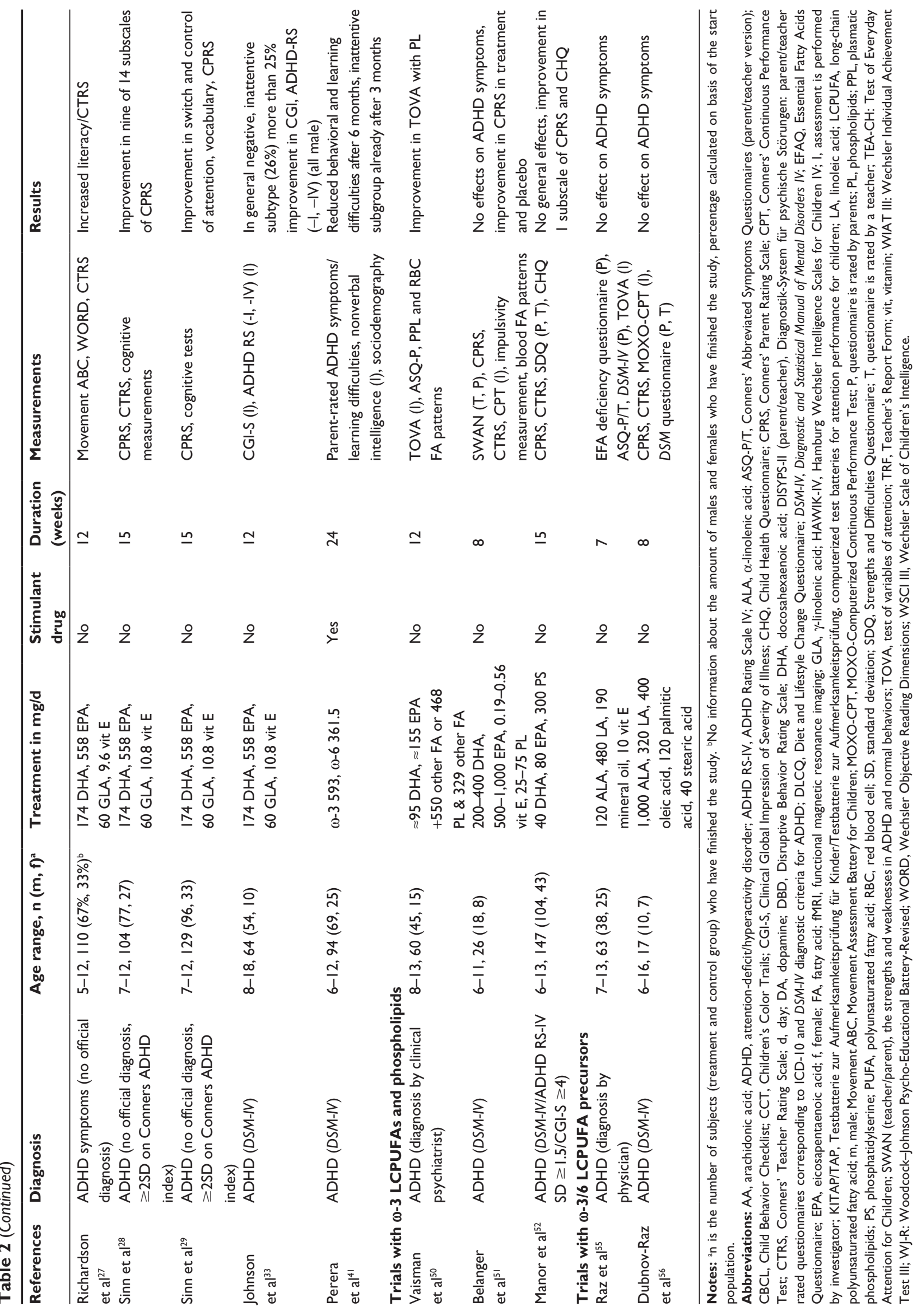


In comparison with other studies, the dietary composition in the study of Sorgi et $\mathrm{al}^{39}$ and Germano et $\mathrm{al}^{11}$ is remarkable because of the use of high amounts of EPA and DHA. The supplement contained 5,400 mg DHA and 10,800 mg EPA/2,202 mg DHA and 4,149 mg EPA, while other studies used a maximum of $174 \mathrm{mg}$ DHA and $558 \mathrm{mg}$ EPA. In the remaining study, ALA was used instead of DHA and EPA, which is, in fact, a precursor of DHA and EPA. This is surprising because it is presumed that the processing of the precursors of $\omega-3 / 6$ fatty acids in the human body is less effective. ${ }^{14}$

\section{Results of double-blind placebo- controlled trials}

An overview of the double-blind trials with placebo groups can be found in Table 2. These studies are classified in accordance with the different compositions used in the PUFA supplements. There is only limited information provided about the rationale for the used PUFA concentrations provided to the participants. Most studies used combinations that were already successfully tested in earlier trials. At the moment, there are no studies that performed dose response of $\omega-3$ PUFAs treatment in ADHD. It is of importance that future studies will address this.

\section{Treatment based on $\omega-3$ LCPUFAs only}

$\omega$-3 LCPUFAs treatment was tested in four studies..$^{30,31,37,43,44}$ In all these studies, the majority of children was treated with stimulant medication. The used type and amount of $\omega-3$ PUFA differed between trials: In one study, only DHA (345 mg per day), in combination with a prescribed stimulant medication, was used. ${ }^{31}$ This study failed to show improvement in ADHD symptoms on the basis of measurements with regard to attention and impulsivity and parent-rated behavior. ${ }^{31}$ Three other studies showed a significant improvement in some ADHD symptoms: Hirayama et $\mathrm{al}^{37,43}$ found improvement in parent-rated hostility and teacher-rated aggression using a treatment of $514 \mathrm{mg}$ DHA and $100 \mathrm{mg}$ EPA per day. Six subjects (15\%) used stimulant medication besides the food supplement. A treatment with $195 \mathrm{mg}$ DHA, $635 \mathrm{mg}$ EPA, $100 \mathrm{mg}$ other $\omega-3 \mathrm{FA}$ in combination with stimulant medication led to improvement in scores on the parent-rated Conners' Abbreviated Symptom Questionnaires, as well as a decrease in inflammation and oxidative stress. ${ }^{44}$ The study of Bos et $\mathrm{al}^{30}$ demonstrated improvement after treatment in both the ADHD group and the control group as based on the parent-rated Child Behavior Checklist. The treatment used consisted of $650 \mathrm{mg}$ DHA and EPA.
In conclusion, single treatment with DHA alone does not show promising results. ${ }^{31}$ However in this study, all the participants were taking stimulant medication while assessing behavior. ${ }^{45}$ The stimulant medication was able to ameliorate behavioral symptoms thereby leaving little room for further improvement by DHA. On the other hand, a combination of DHA with EPA resulted in improvement of some ADHD symptoms. ${ }^{30,37,43,44}$ The results of Hirayama et $\mathrm{al}^{37,43}$ were not included in this conclusion because of the subject population that was used; the study comprised eight subjects (20\%) of whom diagnosis of ADHD is arbitrary and not clear whether they could be diagnosed with ADHD, if rated by DSM-IV criteria. Furthermore, the treatment with stimulant drugs was inconsistent, and there was a high percentage of variable comorbidities, for example, subjects with Asperger's syndrome, conduct disorder, learning disorder, or mood disorder were included. Moreover, the study was carried out in Japan where intake of $\omega-3$ fatty acids is high due to a high average consumption of fish. ${ }^{45,46}$ In this study, baseline fatty acid levels in blood were neither analyzed nor compared with values of ADHD patients in other countries. The experiment was also underpowered due to its small sample size. An interesting aspect of this study was the treatment that was chosen; instead of providing subjects supplements with fish oil or other fatty acids, the supplements were put in fermented soybean milk, bread rolls, and steamed bread, primarily to mask the taste of fish oil. Another study where other food products were used concerns the study of Bos et $\mathrm{al}^{30}$ supplements or placebos were put in margarine.

\section{Trials with both $\omega-3$ LCPUFAs and vitamin $\mathrm{E}$}

In four trials, vitamin $E$ was added to $\omega-3$ LCPUFAs as a measure to protect against easy oxidization of LCPUFAs. ${ }^{32,34,35,47-49}$ In all these studies, a combination of $10-15 \mathrm{mg}$ vitamin $\mathrm{E}$ with $\omega$-3 LCPUFAs was given to children who did not take any stimulant treatment. In two studies, a food supplement with a low amount of DHA and a high amount of EPA (2.7 mg DHA +500 mg EPA/120 mg DHA +600 mg EPA) was used. ${ }^{32,47}$ In general, these studies failed to show positive effects. Based on the teachers rated Conners Rating Scale, only one study found improvement in one, later-defined subgroup as far as oppositional behavior and hyperactivity/ impulsivity are concerned. ${ }^{32}$ Two other studies by Milte et $\mathrm{al}^{34,35}$ in 2012 and 2015 compared different ratios of DHA to EPA: 1:10 (108 mg DHA, 1,109 mg EPA) and 4:1 (1,032 mg DHA, $264 \mathrm{mg}$ EPA). These studies also failed to show amelioration of ADHD symptoms. However, improved fatty acid profile in erythrocytes was correlated with 
improvement in outcome measures. The 2012 study showed a correlation with improvement in word reading, parent-rated oppositional behavior, and anxiety/shyness. ${ }^{35}$ This correlation was even stronger in the subtype with learning difficulties. The study performed in 2015 revealed correlations with improvement in literacy, attention, and behavior. It has to be mentioned that there were inconsistencies in compliance in the study performed in 2012. The highest compliances were found in the treatment groups that also showed the largest improvement in blood fatty acid levels. There are some other limitations in this study: an official diagnosis of ADHD was lacking in 50\% of the children included, and also children with comorbidities such as mood or conduct disorders were included.

From the four studies aforementioned, it can be suggested that the ratio between DHA and EPA is not the most important factor in the treatment against ADHD. This suggestion is supported by a study in which it has been shown that processing is, in fact, a vital step. ${ }^{25}$ This means that it is not the ratio, but, in fact, the amount of $\omega$-3 PUFAs which is important. ${ }^{25}$ An addition of vitamin E, together with its antioxidant capacities, did not show any effect either. However, some changes in the fatty acid profile in the blood were correlated with improvement in outcome measurements.

\section{Trials with $\omega-3 / 6$ PUFAs}

Seven trials included treatments containing both $\omega-3$ and $\omega-6$ LCPUFAs. In 2002, Richardson et $\mathrm{al}^{36}$ tested a supplement containing $480 \mathrm{mg}$ DHA, $180 \mathrm{mg}$ EPA, $864 \mathrm{mg} \mathrm{LA}$, $42 \mathrm{mg} \mathrm{AA}, 3 \mathrm{mg}$ vitamin E, and $8 \mathrm{mg}$ thyme oil. This study reported an improvement in the parent-rated Conners Rating Scale. ${ }^{36}$ Subjects were children aged between 8 and 12 years. All had writing and reading problems and were suspected of having ADHD. However, ADHD had not been officially diagnosed and, thus, no stimulant medication had been prescribed. Another issue is the small sample size of 29 participants. In another study, a comparable treatment was used, but with different amounts: $480 \mathrm{mg}$ DHA, $80 \mathrm{mg}$ EPA, $96 \mathrm{mg}$ GLA instead of the precursor LA, $40 \mathrm{mg}$ AA, and vitamin $\mathrm{E}$ acetate. ${ }^{40}$ In this study, children were taking stimulant medication in combination with the food supplement. Except for an improvement in the ratio of $\omega-3 / \omega-6$ fatty acids in erythrocytes and plasma phospholipids, no other effects were found. However, improvement in behavior was found in both placebo and treatment group. ${ }^{45}$ This suggests that these effects are not specific for the active treatment. Also in this study, the small sample size should be taken into account $(\mathrm{N}=33)$. In a third study, a high concentration of $\omega-3$
LCPUFAs (593 mg) and a low amount of $\omega-6$ LCPUFAs (361.5 mg) in combination with stimulant treatment were used. ${ }^{41}$ It was not specified which particular unsaturated fatty acids were used. After 6 months, a successful reduction in behavioral and learning problems was detected and a significant improvement was already apparent after 3 months of treatment in a subgroup of inattentive subjects. It should be noted that this subgroup was defined after the study had been completed.

In 2005, Richardson et $\mathrm{al}^{27}$ completed a study in which a low DHA and high EPA content with additional $\omega-6$ PUFAs was used (174 mg DHA, $558 \mathrm{mg}$ EPA, $60 \mathrm{mg}$ GLA, and $9.6 \mathrm{mg}$ vitamin E). During experiments, no stimulant medication was taken by any of the children. Almost the same combination of treatment had already been used in three other studies (174 mg DHA, $558 \mathrm{mg}$ EPA, $60 \mathrm{mg}$ GLA, and $10.8 \mathrm{mg}$ vitamin E). ${ }^{28,29,33}$ When comparing these four studies in total, three out of four studies showed a general improvement in ADHD symptoms, such as literacy, and switch and control of attention. This was based on information from the Conners Rating Scales, completed by teachers and parents. The fourth study showed an improvement only in a subgroup of inattentive patients, measured by the ADHD Rating Scale and Clinical Global Impression of Severity of Illness. ${ }^{33}$

In summary, a treatment with $\omega-3$ fatty acid DHA and EPA in combination with $\omega-6$ fatty acids GLA or LA and vitamin E seems to be effective in treating ADHD symptoms. ${ }^{27-29,36,41}$ The treatment with $174 \mathrm{mg}$ DHA, $558 \mathrm{mg}$ EPA, $60 \mathrm{mg}$ GLA, 9.6 or $10.8 \mathrm{mg}$ vitamin $\mathrm{E}$ was tested in four studies, which led to promising results: ${ }^{27-29,33}$ Three studies succeeded in showing improvement in ADHD symptoms. One of these studies and the study supplementing $593 \mathrm{mg} \omega-3$ PUFAs and $361.5 \mathrm{mg} \omega-6$ PUFAs reported more improvement in the inattentive subtype. ${ }^{33,41}$ However, these subgroups were defined after studies had been completed. In further research, it is recommendable to repeat the same treatment but define the different subtypes before starting the study and include all of these different subtypes in the investigation.

\section{Trials with $\omega-3$ LCPUFAs and phospholipids}

Apart from $\omega-3$ fatty acids, phospholipids were also included in three of the studies during treatment. ${ }^{50-52}$ It has been demonstrated in animal studies that phospholipids can function as carriers for $\omega-3$ LCPUFAs in order to increase the availability of the LCPUFAs for uptake in the body. ${ }^{53,54}$ Subjects using stimulant medication were excluded in all of these three studies. In the trial of Vaisman et al, ${ }^{50}$ one of the following combinations was used; either $95 \mathrm{mg}$ DHA, 
$155 \mathrm{mg}$ EPA, and $550 \mathrm{mg}$ other saturated and unsaturated fatty acids or $468 \mathrm{mg}$ phospholipids and $329 \mathrm{mg}$ other fatty acids. When checked against the criteria set in the Test of Variables of Attention, only the treatment with additional phospholipids led to an increase in scores. In another study, the concentration of dietary components in the supplements used was determined based on the participant's body weight. ${ }^{51}$ For example, children with a body weight between 26 and $35 \mathrm{~kg}$ were treated with $300 \mathrm{mg}$ DHA, $750 \mathrm{mg}$ EPA, $38 \mathrm{mg}$ vitamin $\mathrm{E}$, and $50 \mathrm{mg}$ plasma phospholipids. In this particular study, the treatment failed to show any effect. However, when checked against the criteria set in the parent- and teacherrated Conners Rating Scale, another unexpected improvement was found in the treatment group as well as the placebo group. A major criticism of this study is the small sample size $(\mathrm{N}=26)$. The study of Manor et $\mathrm{al}^{52}$ used food supplements containing $40 \mathrm{mg}$ DHA, $80 \mathrm{mg}$ EPA, and $300 \mathrm{mg}$ phosphatidylserine. Results did not show any effect, except for improvement in the restless/impulsive subscale rating of the Conners Rating Scale for parents and the parent impact-emotional subscale of the Child Health Questionnaire. One explanation could be the small number of participants $(\mathrm{N}=17)$.

In conclusion, there is little evidence that a combination of phospholipids and $\omega-3$ FA can affect ADHD symptoms. As shown in the study of Manor et al, ${ }^{52}$ there is only little evidence as to whether this has an effect on treating ADHD. This study included behavioral ratings from teachers who were not trained to rate ADHD symptoms. These teachers had up to 42 children in a classroom, and some of these teachers were replaced during the period of study. More positive effects could possibly be found when improving the rating quality to be filled in by teachers. Further studies should be performed before drawing any other conclusions about the effect of $\omega$-LCPUFAs in combination with phospholipids on ADHD symptoms.

\section{Trials with $\omega-3 / \omega-6$ LCPUFA precursors}

Precursors of $\omega-3 / \omega-6$ LCPUFAs were used in two studies. ${ }^{55,56}$ In the first study, a combination of $120 \mathrm{mg}$ ALA, $480 \mathrm{mg}$ LA in combination with $190 \mathrm{mg}$ mineral oil and $10 \mathrm{mg}$ vitamin $\mathrm{E}$ was used, but this combination failed to show any improvement in ADHD symptoms. ${ }^{55}$ The second study used a much higher amount of ALA (1,000 mg ALA including $320 \mathrm{mg}$ LA, $400 \mathrm{mg}$ oleic acid, $120 \mathrm{mg}$ palmitic acid, and $40 \mathrm{mg}$ stearic acid), but lacked any positive results as well. ${ }^{56}$ This supports the argument that intake of $\omega-3 / \omega-6$ PUFA precursors has a lower efficiency than intake of $\omega-3 / \omega-6$ LCPUFAs, probably due to the low processing efficiency of the precursors. ${ }^{14}$ Furthermore, there is evidence that ALA-rich diets reduce the conversion rate from ALA to EPA, while it increases the oxidation rate of ALA. ${ }^{57}$

\section{General conclusion}

The results of the studies described above are inconsistent. All trials without placebo group showed positive results. These results should be interpreted with care, however, because a placebo group is missing. The study of Barragán et $\mathrm{al}^{26}$ had an interesting design in which effects of a food supplement were compared to effects of stimulant medication as well as the combination of both. It would be helpful to repeat this study in a double-blind design including the use of a placebo group in order to get more information about the possibility to reduce the amount of given stimulant medication.

Adding a placebo group and using a double-blind study design only led to positive results in few studies. There was little evidence that the single $\omega-3$ LCPUFAs treatment had any effect on ADHD symptoms. Studies that had shown positive effects used very small number of participants $(n=9)$ or had a high variability in ADHD diagnosis in combination with comorbidities. ${ }^{37,44}$ The study of Bos et $\mathrm{al}^{30}$ demonstrated a positive effect both in the ADHD group and in the control group when using an active treatment of $650 \mathrm{mg}$ DHA and EPA. This suggests that an improvement of behavior through additional $\omega-3$ LCPUFAs is not ADHD-specific. Adding vitamin E to $\omega-3$ LCPUFAs did not show any convincing results either. Only in one study, an improvement in the hyperactive and impulsive subgroup could be found. ${ }^{32}$ The division in subgroups was however exerted after finishing the study. In order to obtain more reliable results, this study should be repeated after a clear division of subtypes has been realized before the start of the study, thus resulting in getting more information about the effect of $\omega-3$ treatment in combination with vitamin $\mathrm{E}$ in the hyperactive/impulsive subtype.

Treatment with a combination of $\omega-3$ and $\omega-6$ LCPUFAs showed much more promising results. Positive results on ADHD symptoms were found in five studies. In several studies, a treatment with $174 \mathrm{mg}$ DHA, $558 \mathrm{mg}$ EPA, $60 \mathrm{mg}$ GLA, 9.6 or $10.8 \mathrm{mg}$ vitamin E particularly showed promising results. ${ }^{27-29}$ In four of these studies, however, children without ADHD diagnosis were also included. The only study that used the same treatment in officially diagnosed ADHD patients did not show any effect. ${ }^{33}$ On the basis of two questionnaires, the only improvement could be detected in the inattentive subtype. ${ }^{33}$ On the whole, studies where a combination of $\omega$-3 and phospholipids was used, showed negative results, except for the study of Manor et al. ${ }^{52}$ Even though the 
last combination with $\omega-3$ and $\omega-6$ precursors failed to show any improvement during testing. This outcome reinforces the idea that the processing mechanism in the human body has a low efficiency for $\omega-3$ and $\omega-6$ precursors. ${ }^{14}$

\section{Critical analysis of the study design Sample size}

A general discussion point is the underpowering of some the studies due to small number of subjects, which makes it difficult to show any effect whatsoever. ${ }^{58}$ In order to get sufficient statistical power, Bloch and Qawasmi ${ }^{59}$ set up a meta-analysis in which they calculated a sample size of at least 330 participants. This is especially a problem in studies where a heterogenic patient population is used. Heterogeneity in patient groups is created by different subtypes of ADHD, different comorbidities, inconsistency in the treatment of ADHD with stimulant medication, and differences in age and sex.

\section{Age and sex}

The age of the participants ranged from 3.5 to 18 years. The majority of the children were school-aged between 6 and 13 years. This age range covers all ages where ADHD occurs the most. However, ADHD persist also until adulthood, and it would be useful to include also subjects $>18$ years in trials with $\omega$-3-containing food supplements.

One should also carefully consider conclusions drawn about differences in sex because there are mostly more male than female participants included in the trials. A study with $\omega-3$ PUFA supplementation in rats showed that there are sex differences concerning hyperactivity and impulsiveness symptoms; a clear improvement in hyperactivity and impulsiveness symptoms could be detected in male rats, whereas in females, there were no effects or oppositional effects instead. ${ }^{60}$ The changes in male rats were associated with changes in the neurotransmitter turnover in the brain. Furthermore, the conversion efficiency of ALA into EPA and DHA seems to be higher in women than in men. ${ }^{61,62}$ This is in line with the higher prevalence of ADHD in men than in women. The study was performed with reproductive women and suggested a potential effect from estrogens on the conversion from ALA into DHA. These results suggest that it is more important for men to consume the intermediate EPA and final product DHA than their precursor ALA, due to the low efficiency of ALA processing. It was proven that a higher intake of ALA failed to show an increased amount of DHA in the erythrocytes membrane in men while there was a successful conversion to DHA. ${ }^{62}$ Another study suggested differences between women and men in processing speed and physiological needs. ${ }^{25}$ The influence of estrogen was also mentioned here.

\section{Treatment}

The composition and the amount of the different dietary lipid components in the supplements varied between the studies. This makes comparison of the results of different studies difficult. To determine effective treatment compositions, dose-response trials should also be performed in future studies. Furthermore, there is only limited information provided on which a certain composition was based. Often, treatment compositions from earlier studies were reused. In addition, the use of food supplements in participants on stimulant medication has to be considered: it is difficult to find the effects of supplements on top of the improvement due to stimulant medication. Also the baseline levels of ADHD symptoms can be biased because the stimulant medication already suppresses the symptoms of ADHD.

\section{Study period}

Trials usually lasted 8 or 12 weeks. In comparison with this, the 36-week study of Barragán et $\mathrm{al}^{26}$ was really long. The length of the studies should depend on the recovery time of the fatty acid profile both in the blood and in the brain. Evidence from a rat study in which DHA recovery was measured after DHA deficiency showed that the level of recovery in serum is $93 \%$ after 4 weeks and $106 \%$ after 8 weeks. ${ }^{63}$ Brain recovery reached a lower percentage of merely $80 \%$ after 8 weeks. Additionally, it should be considered that blood fatty acid profiles may be not representative for brain fatty acid contents, especially not in subjects who are younger than 18 years. ${ }^{19}$ Moreover, long-term effects should be tested in periods lasting much longer than 8 weeks. The study of Perera et $\mathrm{al}^{41}$ measured the effect of treatment after 3 and 6 months. In general, they found a reduction in behavioral and learning difficulties after 6 months. ${ }^{41}$ In the inattentive subtype, this was already visible after 3 months. This indicates that treatment effects could be seen much later than in 8 up to 12 months, a period of time that is used in most studies. Taking trial lengths together with the recovery time of fatty acid profiles into consideration suggests that trials should not be shorter than 8 weeks. A longer treatment is advisable, however, in order to find effects that can only be detected after a longer period of supplementation and that depend on the recovery of fatty acid profiles.

\section{Assessment}

In general, a low number of different measurements was used in the studies which, moreover, varied between the trials. 
This makes comparisons between the studies difficult. In most cases, only two or three different questionnaires or tests were conducted to investigate ADHD symptoms. Some studies additionally measured the fatty acid profile in the blood which is also considered as appropriate estimation of the brain fatty acid content. However, there is evidence that under the age of 18 , the blood fatty acid content is correlated to the brain fatty acid content only to a certain extent. ${ }^{19}$ Questionnaires often depended on ratings given by parents or teachers. A problem with the parents' ratings is the comprehension of the questionnaires. When completing the Child Behavior Checklist, Widenhorn-Müller et $\mathrm{al}^{47}$ found that parents might have problems understanding the questions correctly. ${ }^{47}$ Parents were asked to rate and explain the children's behavior. Ratings were given, but the description of behavior was often missing due to a possible lack of comprehension. This problem was solved in the study of Germano et $\mathrm{al}^{11}$ in which parents were trained to rate their child's behavior. ${ }^{11}$ It should be considered that all questionnaires are subjective, consequently influencing the results. Another problem with teacher-rated questionnaires are factors such as holidays, the occurrence of big pupil groups, and only a small number of contact hours with the subject. ${ }^{28,52}$ In trials that were not blinded, prior knowledge of giving active treatment could influence the judgment of teachers, parents, and physicians alike. In conclusion, trials differed in many ways, which makes it difficult to make a comparison and to estimate the reliability of results. For future studies, homogeneous groups of subjects and a clear division between the subtypes are advisable.

\section{Safety and tolerability}

To provide an alternative to stimulant medication, it is necessary to consider the safety and tolerability of the $\omega-3$ PUFA food supplements. Food supplements that have been described in this critical appraisal showed a good tolerability in general. Tolerability can be judged by the dropout rate and its reported side effects in relation to aversive events. In all these reviewed studies, only a few participants dropped out because of aversive events. Most common side effects during treatments with an $\omega-3$ PUFA supplement were related to gastrointestinal discomfort, such as stomach ache, feeling sick, and diarrhoea..$^{28,33,55}$ Nose bleeds were also reported, but far less frequent. ${ }^{28,32,34}$ One study investigated the safety of phosphatidylserine-containing supplements over a period of 30 weeks. ${ }^{64}$ During the first 15 weeks, double-blind and placebo-controlled trials were carried out followed by a 15-week open-labeled extension phase. During the first 15 weeks, a combination of $300 \mathrm{mg}$ phosphatidylserine,
$80 \mathrm{mg}$ EPA, and $40 \mathrm{mg}$ DHA was given. During the openlabeled phase, half of this amount was given. Results showed no effect on physical parameters and no differences between placebo groups and treatment groups. This study concluded that the tested treatment was well tolerated.

Tolerability of $\omega-3$ LCPUFAs in ADHD patients has not been investigated in studies lasting longer than 36 weeks yet. $^{26,28,29}$ In two studies, lasting 30 and 36 weeks each, a treatment of $174 \mathrm{mg}$ DHA, $558 \mathrm{mg}$ EPA, and $60 \mathrm{mg}$ GLA and in one study $10.8 \mathrm{mg}$ vitamin E was given. Gastrointestinal discomfort and incidental nose bleeds were side effects reported by only some subjects. Two other subjects indicated a loss of appetite. Similar side effects, also in rare cases, were found in another study with regard to behavioral problems in children between 8 and 16 years. ${ }^{65}$ During this study, a double-blind trial with 100 participants in total was carried out. These participants were divided into a placebo group and a treatment group. Treatment consisted of a combination of $300 \mathrm{mg}$ DHA, $200 \mathrm{mg}$ EPA, $400 \mathrm{mg}$ ALA, and $100 \mathrm{mg}$ DPA. It can be noted that different quantities of $\omega-3$ LCPUFAs were given in the reviewed studies. Tolerability of the food supplements did not seem to be affected however. Moreover, the use of higher amounts of LCPUFAs such as 2,202 mg DHA, 4,149 mg EPA, $461 \mathrm{mg} \omega-6$, and $1,137 \mathrm{mg}$ other fatty acids or $5,400 \mathrm{mg}$ DHA and $10,800 \mathrm{mg}$ EPA were well tolerated by the participants. ${ }^{11,39}$ Side effects of a $\omega-3$ LCPUFAs treatment, in comparison with treatment with methylphenidate, were analyzed in the study of Barragán et al. ${ }^{26}$ The most reported side effect was loss of appetite, which was found in 53\% of participants taking the methylphenidate supplement but only in $27 \%$ of participants taking an additional food supplement.

When summarizing the tolerability of treatment, it can be concluded that there are no reports about severe side effects. The most frequently reported side effects were gastrointestinal discomfort and incidental nose bleeds but in comparison with methylphenidate much less side effects occur. Well-known side effects of a treatment with regard to a methylphenidate treatment are decreased appetite, insomnia, and headaches. ${ }^{8,9}$ This makes a treatment with $\omega$-3 LCPUFAs all the more attractive, as a less harmful alternative for methylphenidate or any other stimulant medication.

\section{Patient-focused perspective}

The most important reason to treat ADHD are problems in daily life specifically in the family environment, at school, or at work. The most common treatment for ADHD is stimulant medication. However, this treatment has often been criticized because of its severe side effects. Examples are 
insomnia and decreased appetite, which are more often found in younger and smaller children. ${ }^{9}$ In children with milder forms of ADHD, parents often decide not to give stimulant medication because the positive effects do not outweigh the side effects. An alternative with less harmful side effects is desirable for this group, particularly, resulting in making their daily life situations easier and to increase the quality of life. In order to reach this goal, treatments with food supplements containing $\omega$-3 LCPUFAs could be a good solution. This critical appraisal of reviewed studies shows that there is a good basis for treatments with $\omega-3$ LCPUFAs. Compliance rates with regard to these treatments were usually high. Most frequently reported problems are in comparison to stimulant medication. These were difficulties in swallowing capsules and a dislike of the fishy taste of the supplement, which led to a rejection of capsules in some cases. ${ }^{34-36,50,56}$ The studies of Hirayama et $\mathrm{al}^{37}$ and Bos et $\mathrm{al}^{30}$ showed a solution to these two difficulties; the fishy taste was masked as the supplement was put in soybean milk, bread rolls, and steamed bread or margarine, and the portions of which were given to patients at a daily basis. ${ }^{37}$ However, it is a questionable way of deliver PUFAs this way because it has to be considered that margarine could increase the risk of oxidations.

\section{Conclusion and place in therapy}

This review aimed to identify effective treatment compositions of $\omega-3$ PUFA food supplements, its safety and tolerability, and the quality of design of the studies. Reviewed studies show inconsistent results. Therefore, clear convincing effects of LCPUFAs supplements to decrease ADHD symptoms are still lacking. The most promising results are found in trials where treatments combining $\omega-3$ and $\omega-6$ LCPUFAs were given. The tolerability of supplements was good, and only mild side effects such as gastrointestinal discomfort and very incidental bleeds were reported. The main issues of the study design are small sample sizes, high variability in study design, and exerted assessment methods. Future studies should include sufficient participants in double-blind and placebo-controlled trials. To make the results easier to compare, blood fatty acid measurements should be included to provide a more reliable assessment of $\omega$ - 3 baseline levels and possible improvements.

Two particular patient groups could benefit from a possible treatment with $\omega-3$ PUFAs: First, LCPUFAs treatment could replace stimulant treatment for patients with mild forms of ADHD. In this patient group, side effects of stimulant medication outweigh the benefits. This leads to untreated cases of ADHD which, in turn, results in an increase in problems in daily life. The second group consists of patients who suffer both from severe ADHD and from side effects of the stimulant treatment. In this patient group, a combination of stimulant medication with $\omega$-3 food supplements could reduce the given amount of stimulant medication, in order to reduce the suffering from side effects. Further studies are suggested to demonstrate the effects of food supplements with $\omega-3$ LCPUFAs on ADHD symptoms.

\section{Disclosure}

The authors report no conflicts of interest in this work.

\section{References}

1. American Psychiatric Association. Diagnostic and Statistical Manual of Mental Disorders. 5th ed. Arlington (VA): American Psychiatric Association; 2013.

2. Thomas R, Sanders S, Doust J, Beller E, Glasziou P. Prevalence of attention-deficit/hyperactivity disorder: a systematic review and metaanalysis. Pediatrics. 2015;135(4):E994-E1001.

3. Kessler RC, Adler L, Barkley R, et al. The prevalence and correlates of adult ADHD in the United States: results from the National Comorbidity Survey Replication. Am J Psychiatry. 2006;163(4):716-723.

4. Polanczyk G, de Lima MS, Horta BL, Biederman J, Rohde LA. The worldwide prevalence of ADHD: a systematic review and metaregression analysis. Am J Psychiatry. 2007;164(6):942-948.

5. Dewey D, Kaplan BJ, Crawford SG, Wilson BN. Developmental coordination disorder: associated problems in attention, learning, and psychosocial adjustment. Human Mov Sci. 2002;21(5-6): 905-918.

6. Berger I, Dor T, Nevo Y, Goldzweig G. Attitudes toward attentiondeficit hyperactivity disorder (ADHD) treatment: parents' and children's perspectives. J Child Neurol. 2008;23(9):1036-1042.

7. Wigal SB, Gupta S, Greenhill L, et al. Pharmacokinetics of methylphenidate in preschoolers with attention-deficit/hyperactivity disorder. JChild Adolesc Psychopharmacol. 2007;17(2):153-164.

8. Lee J, Grizenko N, Bhat V, Sengupta S, Polotskaia A, Joober R. Relation between therapeutic response and side effects induced by methylphenidate as observed by parents and teachers of children with ADHD. BMC Psychiatry. 2011;11(1):70.

9. Stein MA, Sarampote CS, Waldman ID, et al. A dose-response study of OROS methylphenidate in children with attention-deficit/hyperactivity disorder. Pediatrics. 2003;112(5):e404.

10. Antalis CJ, Stevens LJ, Campbell M, Pazdro R, Ericson K, Burgess JR. Omega-3 fatty acid status in attention-deficit/hyperactivity disorder. Prostaglandins Leukot Essent Fatty Acids. 2006;75(4-5):299-308.

11. Germano M, Meleleo D, Montorfano G, et al. Plasma, red blood cells phospholipids and clinical evaluation after long chain omega-3 supplementation in children with attention deficit hyperactivity disorder (ADHD). Nutr Neurosci. 2007;10(1-2):1-9.

12. Chen JR, Hsu SF, Hsu CD, Hwang LH, Yang SC. Dietary patterns and blood fatty acid composition in children with attention-deficit hyperactivity disorder in Taiwan. J Nutr Biochem. 2004;15(8): 467-472.

13. Colter AL, Cutler C, Meckling KA. Fatty acid status and behavioural symptoms of attention deficit hyperactivity disorder in adolescents: a case-control study. Nutr J. 2008;7:8.

14. James MJ, Ursin VM, Cleland LG. Metabolism of stearidonic acid in human subjects: comparison with the metabolism of other n-3 fatty acids. Am J Clin Nutr. 2003;77(5):1140-1145.

15. Ervin RB, Wright JD, Wang CY, Kennedy-Stephenson J. Dietary intake of fats and fatty acids for the United States population: 1999-2000. Adv Data. 2004;(348):1-6. 
16. Kuipers RS, Luxwolda MF, Dijck-Brouwer DA, et al. Estimated macronutrient and fatty acid intakes from an East African Paleolithic diet. Br J Nutr. 2010;104(11):1666-1687.

17. Simopoulos AP. The importance of the omega-6/omega-3 fatty acid ratio in cardiovascular disease and other chronic diseases. Exp Biol Med. 2008;233(6):674-688

18. Bagga D, Wang L, Farias-Eisner R, Glaspy JA, Reddy ST. Differential effects of prostaglandin derived from omega- 6 and omega-3 polyunsaturated fatty acids on COX-2 expression and IL-6 secretion. Proc Natl Acad Sci U S A. 2003;100(4):1751-1756.

19. Carver JD, Benford VJ, Han B, Cantor AB. The relationship between age and the fatty acid composition of cerebral cortex and erythrocytes in human subjects. Brain Res Bull. 2001;56(2):79-85.

20. Stockard JE, Saste MD, Benford VJ, Barness L, Auestad N, Carver JD Effect of docosahexaenoic acid content of maternal diet on auditory brainstem conduction times in rat pups. Dev Neurosci. 2000;22(5-6): 494-499.

21. Uauy R, Hoffman DR, Peirano P, Birch DG, Birch EE. Essential fatty acids in visual and brain development. Lipids. 2001;36(9):885-895.

22. van Goor SA, Dijck-Brouwer DA, Doornbos B, et al. Supplementation of DHA but not DHA with arachidonic acid during pregnancy and lactation influences general movement quality in 12-week-old term infants. Br J Nutr. 2010;103(2):235-242.

23. Ahmad A, Moriguchi T, Salem N. Decrease in neuron size in docosahexaenoic acid-deficient brain. Pediatr Neurol. 2002;26(3):210-218.

24. Sinn N. Physical fatty acid deficiency signs in children with ADHD symptoms. Prostag Leukotr Ess. 2007;77(2):109-115.

25. Dias CB, Wood LG, Phang M, Garg ML. Kinetics of omega-3 polyunsaturated fatty acids when co-administered with saturated or omega-6 fats. Metab Clin Exp. 2015;64(12):1658-1666.

26. Barragán E, Breuer D, Dopfner M. Efficacy and Safety of omega-3/6 fatty acids, methylphenidate, and a combined treatment in children with ADHD. J Atten Disord. 2014;31(6):1-9.

27. Richardson AJ, Montgomery P. The Oxford-Durham study: a randomized, controlled trial of dietary supplementation with fatty acids in children with developmental coordination disorder. Pediatrics. 2005;115(5): 1360-1366.

28. Sinn N, Bryan J. Effect of supplementation with polyunsaturated fatty acids and micronutrients on learning and behavior problems associated with child ADHD. J Dev Behav Pediatr. 2007;28(2):82-91.

29. Sinn N, Bryan J, Wilson C. Cognitive effects of polyunsaturated fatty acids in children with attention deficit hyperactivity disorder symptoms: a randomised controlled trial. Prostaglandins Leukot Essent Fatty Acids. 2008;78(4-5):311-326.

30. Bos DJ, Oranje B, Veerhoek ES, et al. Reduced symptoms of inattention after dietary omega-3 fatty acid supplementation in boys with and without attention deficit/hyperactivity disorder. Neuropsychopharmacology. 2015;40(10):2298-2306

31. Voigt RG, Llorente AM, Jensen CL, Fraley JK, Berretta MC, Heird WC. A randomized, double-blind, placebo-controlled trial of docosahexaenoic acid supplementation in children with attention-deficit/hyperactivity disorder. J Pediatr. 2001;139(2):189-196.

32. Gustafsson PA, Birberg-Thornberg U, Duchen K, et al. EPA supplementation improves teacher-rated behaviour and oppositional symptoms in children with ADHD. Acta Paediatrica. 2010;99(10):1540-1549.

33. Johnson M, Ostlund S, Fransson G, Kadesjo B, Gillberg C. Omega-3/ omega-6 fatty acids for attention deficit hyperactivity disorder: a randomized placebo-controlled trial in children and adolescents. J Atten Disord. 2009;12(5):394-401.

34. Milte CM, Parletta N, Buckley JD, Coates AM, Young RM, Howe PR. Increased erythrocyte eicosapentaenoic acid and docosahexaenoic acid are associated with improved attention and behavior in children with ADHD in a randomized controlled three-way crossover trial. J Atten Disord. 2015;19(11):954-964.

35. Milte CM, Parletta N, Buckley JD, Coates AM, Young RM, Howe PR. Eicosapentaenoic and docosahexaenoic acids, cognition, and behavior in children with attention-deficit/hyperactivity disorder: a randomized controlled trial. Nutrition. 2012;28(6):670-677.
36. Richardson AJ, Puri BK. A randomized double-blind, placebo-controlled study of the effects of supplementation with highly unsaturated fatty acids on ADHD-related symptoms in children with specific learning difficulties. Prog Neuropsychopharmacol Biol Psychiatry. 2002;26(2):233-239.

37. Hirayama S, Hamazaki T, Terasawa K. Effect of docosahexaenoic acid-containing food administration on symptoms of attention-deficit/ hyperactivity disorder - a placebo-controlled double-blind study. Eur J Clin Nutr. 2004;58(3):467-473.

38. Huss M, Volp A, Stauss-Grabo M. Supplementation of polyunsaturated fatty acids, magnesium and zinc in children seeking medical advice for attention-deficit/hyperactivity problems - an observational cohort study. Lipids Health Dis. 2010;9:105.

39. Sorgi PJ, Hallowell EM, Hutchins HL, Sears B. Effects of an open-label pilot study with high-dose EPA/DHA concentrates on plasma phospholipids and behavior in children with attention deficit hyperactivity disorder. Nutr J. 2007;6:16.

40. Stevens L, Zhang W, Peck L, et al. EFA supplementation in children with inattention, hyperactivity, and other disruptive behaviors. Lipids. 2003;38(10):1007-1021.

41. Perera H, Jeewandara KC, Seneviratne S, Guruge C. Combined omega3 and omega6 supplementation in children with attentiondeficit hyperactivity disorder (ADHD) refractory to methylphenidate treatment: a double-blind, placebo-controlled study. J Child Neurol. 2012;27(6):747-753.

42. Joshi K, Lad S, Kale M, et al. Supplementation with flax oil and vitamin $\mathrm{C}$ improves the outcome of attention deficit hyperactivity disorder (ADHD). Prostaglandins Leukot Essent Fatty Acids. 2006; 74(1):17-21.

43. Hamazaki T, Hirayama S. The effect of docosahexaenoic acid-containing food administration on symptoms of attention-deficit/hyperactivity disorder - a placebo-controlled double-blind study. Eur J Clin Nutr. 2004;58(5):838

44. Hariri M, Djazayery A, Djalali M, Saedisomeolia A, Rahimi A, Abdolahian E. Effect of n-3 supplementation on hyperactivity, oxidative stress and inflammatory mediators in children with attention-deficithyperactivity disorder. Malays J Nutr. 2012;18(3):329-335.

45. Sinn N, Milte C, Howe PRC. Oiling the brain: a review of randomized controlled trials of omega-3 fatty acids in psychopathology across the lifespan. Nutrients. 2010;2(2):128-170.

46. Sekikawa A, Steingrimsdottir L, Ueshima H, et al. Serum levels of marine-derived n-3 fatty acids in Icelanders, Japanese, Koreans, and Americans - a descriptive epidemiologic study. Prostaglandins Leukot Essent Fatty Acids. 2012;87(1):11-16.

47. Widenhorn-Müller K, Schwanda S, Scholz E, Spitzer M, Bode H. Effect of supplementation with long-chain omega-3 polyunsaturated fatty acids on behavior and cognition in children with attention deficit/ hyperactivity disorder (ADHD): a randomized placebo-controlled intervention trial. Prostaglandins Leukot Essent Fatty Acids. 2014;91(1-2): 49-60.

48. Song JH, Fujimoto K, Miyazawa T. Polyunsaturated (n-3) fatty acids susceptible to peroxidation are increased in plasma and tissue lipids of rats fed docosahexaenoic acid-containing oils. J Nutr. 2000;130(12): 3028-3033.

49. Wang Y, Cui P. Reactive carbonyl species derived from omega-3 and omega-6 fatty acids. J Agr Food Chem. 2015;63(28):6293-6296.

50. Vaisman N, Kaysar N, Zaruk-Adasha Y, et al. Correlation between changes in blood fatty acid composition and visual sustained attention performance in children with inattention: effect of dietary n-3 fatty acids containing phospholipids. Am J Clin Nutr. 2008;87(5):1170-1180.

51. Belanger SA, Vanasse M, Spahis S, et al. Omega-3 fatty acid treatment of children with attention-deficit hyperactivity disorder: a randomized, double-blind, placebo-controlled study. Paediatr Child Health. 2009; 14(2):89-98.

52. Manor I, Magen A, Keidar D, et al. The effect of phosphatidylserine containing omega3 fatty-acids on attention-deficit hyperactivity disorder symptoms in children: a double-blind placebo-controlled trial, followed by an open-label extension. Eur Psychiatry. 2012;27(5):335-342. 
53. Wijendran V, Huang MC, Diau GY, Boehm G, Nathanielsz PW, Brenna JT. Efficacy of dietary arachidonic acid provided as triglyceride or phospholipid as substrates for brain arachidonic acid accretion in baboon neonates. Pediatr Res. 2002;51(3):265-272.

54. Hiratsuka S, Ishihara K, Kitagawa T, Wada S, Yokogoshi H. Effect of dietary docosahexaenoic acid connecting phospholipids on the lipid peroxidation of the brain in mice. J Nutr Sci Vitaminol. 2008;54(6): 501-506.

55. Raz R, Carasso RL, Yehuda S. The influence of short-chain essential fatty acids on children with attention-deficit/hyperactivity disorder: a double-blind placebo-controlled study. J Child Adolesc Psychopharmacol. 2009;19(2):167-177.

56. Dubnov-Raz G, Khoury Z, Wright I, Raz R, Berger I. The effect of alpha-linolenic acid supplementation on ADHD symptoms in children: a randomized controlled double-blind study. Front Hum Neurosci. 2014;8:780.

57. Vermunt SH, Mensink RP, Simonis MM, Hornstra G. Effects of dietary alpha-linolenic acid on the conversion and oxidation of 13C-alphalinolenic acid. Lipids. 2000;35(2):137-142.

58. Gow RV, Hibbeln JR, Parletta N. Current evidence and future directions for research with omega-3 fatty acids and attention deficit hyperactivity disorder. Curr Opin Clin Nutr Metabol Care. 2015;18(2):133-138.

59. Bloch MH, Qawasmi A. Omega-3 fatty acid supplementation for the treatment of children with attention-deficit/hyperactivity disorder symptomatology: systematic review and meta-analysis. J Am Acad Child Adolesc Psychiatry. 2011;50(10):991-1000.
60. Dervola KS, Roberg BA, Woien G, et al. Marine omega-3 polyunsaturated fatty acids induce sex-specific changes in reinforcer-controlled behaviour and neurotransmitter metabolism in a spontaneously hypertensive rat model of ADHD. Behav Brain Funct. 2012;8:56.

61. Burdge GC, Wootton SA. Conversion of alpha-linolenic acid to eicosapentaenoic, docosapentaenoic and docosahexaenoic acids in young women. Br J Nutr. 2002;88(4):411-420.

62. Burdge GC, Jones AE, Wootton SA. Eicosapentaenoic and docosapentaenoic acids are the principal products of alpha-linolenic acid metabolism in young men. Brit J Nutr. 2002;88(4):355-363.

63. Moriguchi T, Loewke J, Garrison M, Catalan JN, Salem N Jr. Reversal of docosahexaenoic acid deficiency in the rat brain, retina, liver, and serum. J Lipid Res. 2001;42(3):419-427.

64. Manor I, Magen A, Keidar D, et al. Safety of phosphatidylserine containing omega3 fatty acids in ADHD children: a double-blind placebo-controlled trial followed by an open-label extension. Eur Psychiatry. 2013;28(6):386-391.

65. Raine A, Portnoy J, Liu J, Mahoomed T, Hibbeln JR. Reduction in behavior problems with omega-3 supplementation in children aged 8-16 years: a randomized, double-blind, placebo-controlled, stratified, parallel-group trial. J Child Psychol Psychiatry. 2015;56(5):509-520.

\section{Publish your work in this journal}

Neuropsychiatric Disease and Treatment is an international, peerreviewed journal of clinical therapeutics and pharmacology focusing on concise rapid reporting of clinical or pre-clinical studies on a range of neuropsychiatric and neurological disorders. This journal is indexed on PubMed Central, the 'PsycINFO' database and CAS,

\section{Dovepress}

and is the official journal of The International Neuropsychiatric Association (INA). The manuscript management system is completely online and includes a very quick and fair peer-review system, which is all easy to use. Visit http://www.dovepress.com/testimonials.php to read real quotes from published authors. 